\title{
Forecasting Eruptions in the Circum-Pacific
}

\author{
by J.G. Souther, R.I. Tilling and R.S. Punongbayan
}

\begin{abstract}
Many important advances have been made in the last few years in techniques and approaches to forecasting volcanic eruptions. Yet some of the most dangerous volcanoes are in countries unable to provide either the equipment or the skills to monitor them and to warn endangered residents. This review of the many scientific, technical, social and even political factors involved in volcano forecasting will be of value to other scientists concerned with monitoring and coping with natural hazards and disasters.
\end{abstract}

\begin{abstract}
uneasy residents leaving the city, and Governor Mouttet and his wife travelled from the capital (Fort-de-France) to St. Pierre, in order to show that there was no cause for alarm. Three days later, on the morning of May 8, a glowing avalanche swept through St. Pierre, killing all but two of its 30,000 residents, including the governor and his wife.
\end{abstract}

The contrast between these two cases dramatically illustrates how far the science of forecasting eruptions has advanced - and how far it has yet to go. But Mount St. Helens is in a country where a highly sophisticated response to the precursor events could be mobilized quickly. In many parts of the world the warning signals of Mount St. Helens might have gone undetected or, worse, have been deliberately or unwittingly de-emphasized, as during the tragedy of $\mathrm{Mt}$. Pelée.

\section{Introduction}

The magnitude of the climatic eruption of Mount St. Helens on the morning of May 18, 1980, surprised both scientists and the public. The size and violence of the lateral blast exceeded all expectations, as did the utter devastation it caused. Fortunately, the mountain gave warning weeks earlier. From March 20 onwards, seismic activity, ground deformation and mild phreatic discharges of gas and ash were monitored by volcanologists and interpreted as precursors of an impending, major eruption. The alert was sent out to public officials, who enforced the evacuation of residents from the high-risk zone and prevented sightseers from entering it. When the paroxysmal eruption came, sixty people died, including a member of the monitoring team. But had the warning signals gone undetected, or had the advice of scientists been ignored, the death toll could have been in the thousands.

Seventy-eight years earlier, in late April of 1902, Mont Pelée on the Caribbean island of Martinique awoke from its half century slumber and began to erupt. For the next two weeks, ash periodically fell on the city of St. Pierre and numerous mudflows swept down the valleys on the volcano's upper slopes. Local inhabitants were understandably frightened but were urged by government officials not to flee, because an election was scheduled for May 11 . On May 5, the day that a lahar killed about 30 people, a committee appointed by Governor Louis Mouttet to assess the risks posed by Mont Pelée reported that ". . . the safety of St. Pierre is completely assured." Troops were dispatched to prevent the logist is thus forced to seek that narrow middle course between reacting too soon and waiting too long.

Nowhere is reliable eruption forecasting more vital than in the circum-Pacific region, where more than $50 \%$ of the earth's active and potentially active volcanoes are scattered in the "Ring of Fire." Recent experience by volcanologists in this region confirms the general assumption that is the very essence of eruption forecasting - that volcanoes do behave in a predictable manner. The problem is to obtain and interpret the long-term clues that are the basis for an eruption "forecast" and the short-term warning signals that are the basis for an eruption "prediction."

Although the terms "forecast" and "prediction" often are used synonymously, many voleanologists favour the distinetions in 
usage suggested by Swanson and others (1984, p. 119): "An eruption forecast is a comparatively imprecise and uncertain statement about expected activity. An eruption prediction is a comparatively precise, certain statement of the location, time, and nature of expected activity. Predictions tend to be shorter term and more deterministic than forecasts. Forecasts are often based on extrapolation of past events, whereas predictions are often based at least partly on interpretations of ongoing, monitored changes." Volcanologists from some non-English speaking countries, however, point out that even though the distinction between "forecast" and "prediction" is clear enough in English, it is difficult, if not impossible, to carry it into their own languages.

Long-term forecasts may have little immediate impact on public attitudes toward land use, but they should be heeded where construction of major structures such as dams, power plants, or bridges is planned within a high-risk area. Eruption forecasting is thus an essential component of risk assessment and all the attendant considerations of insurance rates and legal liability.

Eruption forecasting begins with detailed knowledge about a voleano's past history. The investigations of Mount St. Helens (see Lipman and Mullineaux, 1981, for a review) provide a classic example of how systematic mapping and dating of eruption products from a dormant volcano can lead to a forecast of when and how it may erupt anew. Such studies led to an eruption forecast published in 1975 that "Future eruptions of Mount St. Helens are a near certainty" and that an eruption was "likely to occur within the next hundred years, and perhaps even before the end of this century" (Crandell, Mullineaux and Rubin, 1975). That forecast was followed in 1978 by a detailed assessment of potential hazards that might be expected from future eruptions of Mount St. Helens (Crandell and Mullineaux, 1978).

At Mount St. Helens, the documentation of prehistoric eruptions, combined with the wealth of data acquired in 1980-84 on precursor activity, eruption processes and posteruptive activity make it one of the best understood of all arc stratovolcanoes. Predicting its activity has been remarkably successful. Since the climatic eruption of May 18,1980 , voleanologists from the Cascades Volcano Observatory have predicted nearly all of the extrusions and major periods of endogenous growth to within a few days of the actual event.

Figure 2: Drilling a hole in lava flow to install a borehole tiltmeter, Kilauea Volcano.

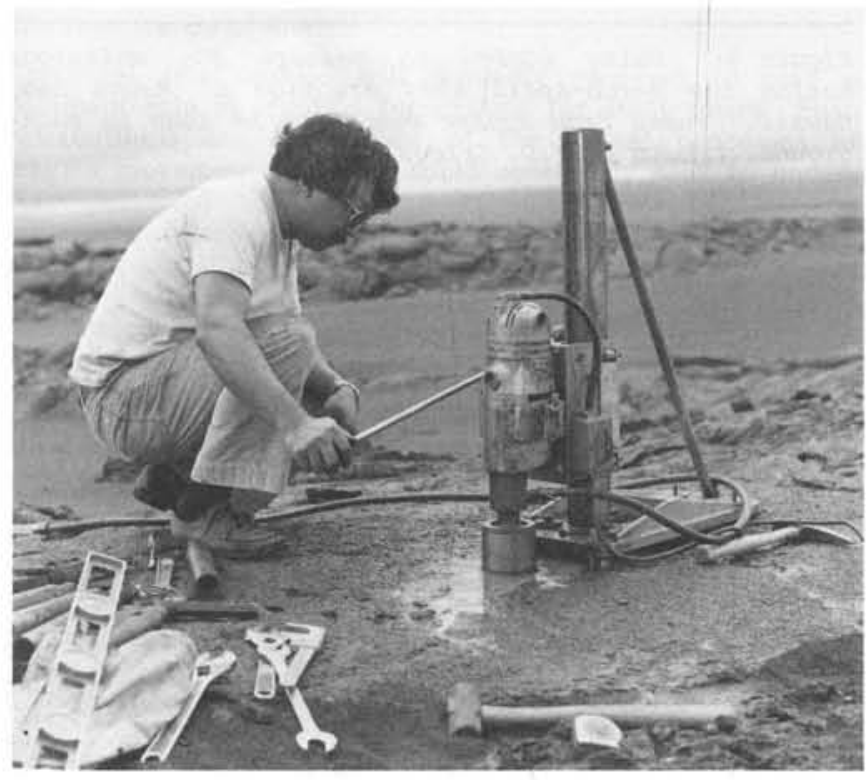

Which Volcanoes to Monitor?

Because of limitations of scientific and monetary resources, not all high-risk voleanoes ean be monitored. Thus one of the first, and often most difficult, decisions faced by voleanologists is selecting where and how their limited resources can best be utilized. This is particularly important in developing countries such as Indonesia, the Philippines and Papua New Guinea, where the large number of potentially dangerous volcanoes (Fig. 1) and limited monitoring capability require that priority be given to the most dangerous.

The geological record provides insights into the size, style and frequency of prehistoric eruptions and, if the volcano has a record of historic activity, it may be possible to anticipate the type and frequency of future eruptions. The assessment of eruption potential, combined with consideration of population density, forms the primary basis for identifying highrisk volcanoes, and thus assigning monitoring priority in Indonesia, the Philippines, U.S.A., and Japan (e.g. Lowenstein, 1982; Sudradjat and Tilling, 1984; Katili and Sudradjat, 1984; Tilling and Bailey, 1984).

\section{Monitoring Techniques}

Most monitoring techniques are designed to detect the movement of magma within the crust before it breaches the surface in an eruption (Unesco, 1971; Civetta et al., 1974; Decker, 1978). During its ascent, magma may fracture the brittle, confining rock to produce discrete earthquakes or earthquake swarms, or the subsurface motion of the magma itself may generate high-frequency seismic vibrations known as volcanic tremor. The roof above an ascending magma column or a swelling reservoir may be uplifted and stretched, producing vertical and horizontal displacements at the surface. Gas and vapour, either directly from the magma or released from the surrounding rock by increasing temperature may be vented to the surface, its chemical composition providing clues to the temperature, depth and ascent or swelling rate of the underlying magma reservoir.

The most reliable and widely used surveillance technique employs a seismic network, capable of monitoring a wide area and recording either real-time, analog data or simply counting seismic events above some pre-selected magnitude or frequency. Several seismometers in an array can provide an almost instantaneous record of both the time and location of magma-induced earthquakes. In combination with ground-deformation measurements, seismicity provides the most reliable real-time monitoring information and earliest procursory signals of impending eruption.

There is a need, however, for a system that is easily transportable, solar powered, with accurate time-keeping components, and radio telemetry from at least four seismometers to a self-contained computer for real-time data processing. Also, at some voleanoes, precursory high-frequency signals have been reported. Though not recorded by standard seismographs, they might be detected by hydrophones installed in boreholes or lakes.

Ground deformation of the volcano's surface occurs over a longer time scale, and weeks, months, or even years of uplift or extension may precede an eruption. Ground-deformation monitoring generally requires measurements to be made with tiltmeters or geodetic stations located close to the volcanic source.

The early tiltmeters at the Hawaiian Volcano Observatory were simple devices made from spent artillery shells, connected with garden hose and filled with water, the water level in the shell cases was read optically by means of a vernier. Modern "wet" tiltmeters (Fig. 2), which also involve a working fluid responding to slope changes, can detect deviations of only a few microradians or less, and the data are telemetered and plotted as cumulative strain on continuous recorders (Westphal et al., 1983). Easier and cheaper to install than the "wet" tilt-measurement systems or electronic instruments are the so called "dry" tilt systems 


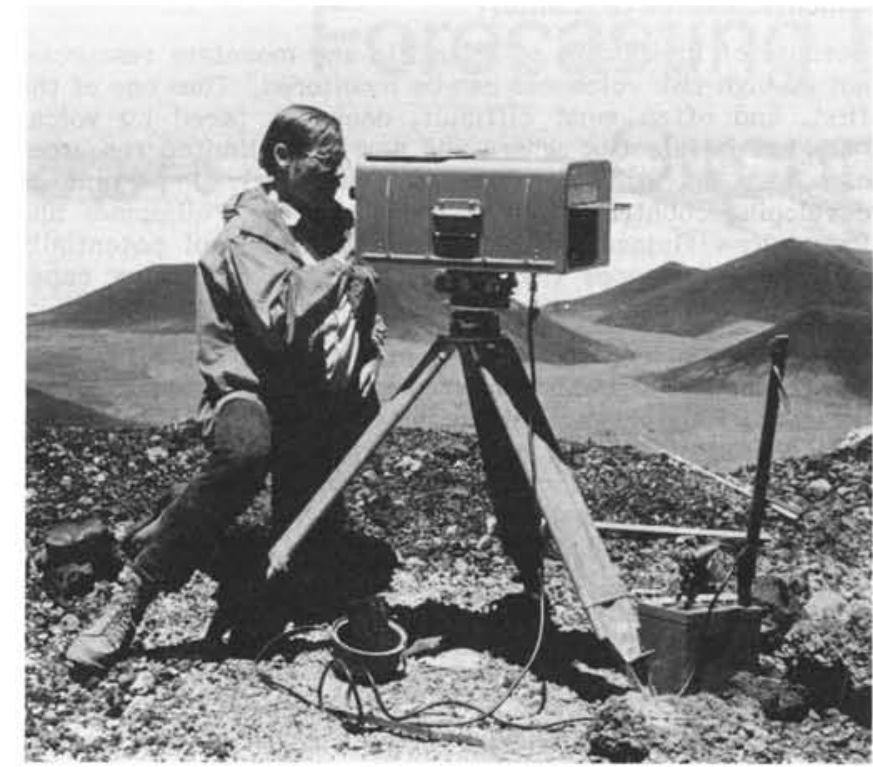

Figure 3: Volcanologist using a laser-beam, electronic distance measurement (EDM) instrument, powered bu 12-volt battery.

that involve precise levelling of arrays by use of optical level and stadia rods. Although "dry" tilt measurements are slightly less accurate, their low cost and portability allow for rapid installation and greater frequency of measurement during a crisis.

Ground deformation is three dimensional, and both vertical and horizontal components should be measured as well as the resulting tilt. A standard theodolite can detect differences of a centimetre per kilometre, which is often adequate, but laser ranging, electronic distance meters (EDMs) have a precision of several millimeters per kilometer (Fig. 3). Both instruments require the establishment of a geodetic grid and repeated measurements over a period of time in order to detect statistically significant ground displacements. Because the most critical measurements are commonly those made closest to the source, the re-occupation of geodetic grids can be one of the more dangerous tasks a voleanologist is required to perform.

Volcanic gases may record geochemical changes taking place over periods of hours, days or sometimes weeks or months. The correlation spectrometer (COSPEC) system (Fig. 4) based on ultraviolet absorption, and the MIRAN system, based on infra-red absorption of sunlight by gases, are used respectively to monitor $\mathrm{SO}_{2}$ and $\mathrm{CO}_{2}$ in volcanic fumes (Casadevall et al., 1983; Stoiber, Williams and Malineonico, in Tazieff and Sabroux, 1983). Both systems have rapidresponse rates and may be either fixed or mounted in vehicles or aircraft. Used from the air, they provide a way to measure the composition and cross sectional area of a volcanic plume and thus to estimate discharge rates of $\mathrm{CO}_{2}$ and $\mathrm{SO}_{2}$. The oxidation of magma as it nears the surface may lead to the release of hydrogen gas, and electrochemical instruments capable of continuous monitoring of hydrogen have been developed (Gantes, Sabroux and Vitter, in Tazieff and Sabroux, 1983; Sato et al., in press).

The movement of magma and accompanying changes in the thermal and stress regime may affect the electromagnetic and/or piezoelectric and other physical properties of rock. Present applications are largely experimental, but several electrical systems appear to have potential as monitoring tools. Self potential (SP) measurements are easy and inexpensive to make and, at Kilauea SP changes of up to $300 \mathrm{mv}$ are common prior to an eruption (Davis et al., 1984; Zablocki,
1976). Real-time changes in the electromagnetic field may be recorded by a Controlled Source Electromagnetic Monitor (CSEM). Although these instruments are not portable anc require considerable electrical energy, they are capable of detecting very deep events (Jackson et al,, in press). Techniques involving measurement of variations in the gravitational field are also being tested in Hawaii and elsewhere (Dzurisin et al., 1980).

Two monitoring systems employing satellites are being tested. A "Global Positioning System," currently in the development stage, is potentially capable of measuring three dimensional displacements of ground sensors to a precision of 1 part per million (Navigation, 1978). Focussed on selectec volcanoes, it would enable virtual real-time monitoring of deformation on a world-wide basis, but the present cost of sensors is prohibitively high, and several would be requirec for, each volcano. Another satellite-based system witr demonstrated potential for voleano monitoring is the Tota Ozone Mapping Spectrometer on board the Nimbus- 7 weather satellite (Krueger, 1983). It is able to distinguish $\mathrm{SO}_{2}$. bearing voleanic clouds from $\mathrm{SO}_{2}$-free atmospheric clouds. thereby providing global surveillance without grounc installations. Combined with radar monitoring of ash-lader plume heights and meteorological data, such a system coulc help evaluate tephra-fallout patterns and define areas of risk to aireraft.

Finally, the importance of frequent and, preferably: continuous visual observation by trained voleano watchers cannot be underestimated. Many of the most useful precursors such as opening fissures, advancing thrust faults, increased fumarolic activity, felt earthquakes, small phreatic eruptions, and snow-melt patterns need no specia] instruments to detect and measure. At the Mount St. Helens dome complex, for example, the rate of change becomes asymptotic to the time of eruption, whether the data are acquired with an EDM or two stakes and a steel tape measure (Swanson et al., 1983). With a few simple tools, some basic training in what to observe, and an awareness of the potentia] danger, the voleano watcher can thus provide a vital first line of defense in areas where more elaborate monitoring systems are unaffordable and/or impractical. In the long run, however, what is needed is integrated, multiple monitoring methods and baseline information collected during quie1 periods to detect the earliest departure from "normal' background conditions.

\section{Precursors - The Empirical Record}

Between brief bursts of activity (Fig. 5), the dynamic processes of a volcano operate slowly. Although all volcanoes

Figure 4: Using COSPEC to measure $\mathrm{SO}_{2}$ emissions during the March-April 1984 eruption of Mauna Lao, Hawail. Fumes from active vents can be seen in background. (Photo by J.D. Griggs).

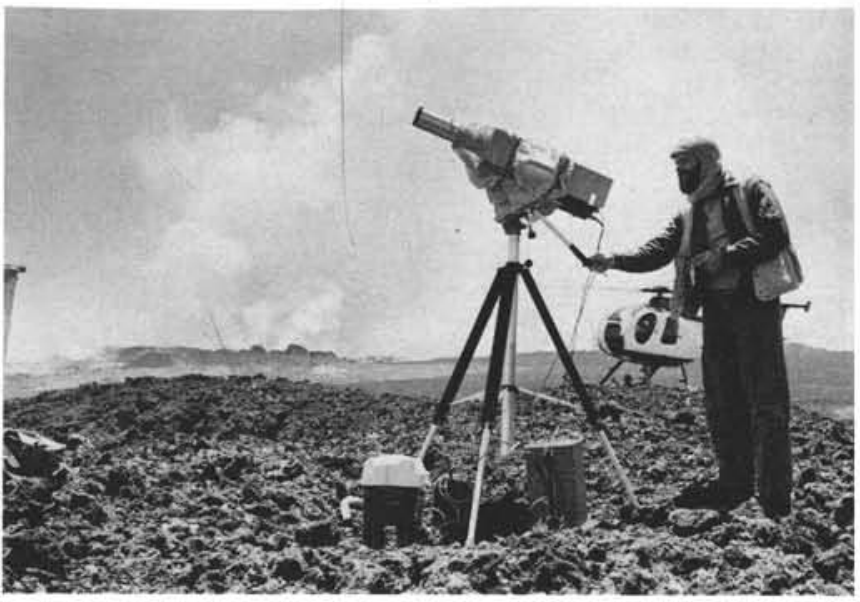


share some common characteristics, no two behave in exactly the same way. The basaltic shield voleanoes of Hawaii and their analogues in Iceland, probably the best understood of all, behave in a reasonably predictable way. They erupt frequently enough to allow repeated observation of the complete cycle (Dzurisin et al., 1984).

At Kilauea, magma ascending from the mantle moves into the central part of the edifice and accumulates in shallow reservoirs (2-4 $\mathrm{km}$ depth), lifting the overlying rock and causing the summit of the mountain to inflate. After a brief residence, typically weeks to months, magma migrates from the reservoir, producing sustained harmonic tremor and abrupt summit deflation - the characteristic signal that magma is "on the move" and an eruption is imminent. Here the eruption mechanism is sufficiently well understood so that precursor events can be related to a model of magma movement.

A regular pattern is also beginning to emerge at Mount St. Helens, where slow, endogenous growth of the summit dome is accompanied by an exponential increase in the rate of strain as the time of extrusion nears (Swanson et al., 1983). However, with the exception of Sakurajima, Asama, Stromboli and a few other regularly active and monitored voleanoes, such well documented relationships are rare.

When a volcano that has been in repose for years or decades shows increased seismicity, ground deformation, thermal activity or other changes, an immediate question is "Have we seen similar unrest before, and what happened?" If the voleano has a history of well-monitored eruptions, it may not be necessary to look beyond that history. But when no such records exist, the only recourse may be to consider eruptions of similar volcanoes around the world.

Seeking historic or prehistoric analogs may require months of literature search and synthesis, but it is important to identify and study such analogs before crises develop. A cooperative USGS-Smithsonian Institution effort is now underway to prepare a computer file on eruption precursor data that will facilitate searches for possible analogs to any developing volcanic crisis. Because of the current unrest at Long Valley (California), the Phlaegraean Fields (Italy), and Rabaul (Papua New Guinea), first priority has been given to compiling precursory-type activity for silicic calderas around the world. Available data indicate that eruptions within calderas are always preceded by precursory activity, but only ten percent of precursory-type episodes are followed by eruptions. The problem remains one of picking the forerunners of actual eruptions from the mass of seismic, deformation and heat flow variations that occur in young and active calderas.

\section{The Importance of Models}

Empirical relationships will probably continue to play a dominant role in eruption forecasting for many years. Such relationships are expressions of the actual processes of magma movement that we should constantly seek to understand better. In the past, the reduction and interpretation of seismic data have assumed perfect horizontal layering, but the real structure of volcanoes is essentially vertical and extremely complex. Improved techniques are needed that will interpret such structures and allow us to build more realistic seismic models.

In addition to structural models based on geological and geophysical surveys, it is important to understand the thermodynamics of magma generation, its rise through the crust and the various physico-chemical mechanisms that trigger and sustain an eruption. This type of theoretical modelling is a principal direction that should be taken by new research and technology.

\section{The Circum-Pacific Ring of Fire}

Compared to those of Hawaii, much less is known about are voleanoes. Yet the voleano data file of the Smithsonian Institution (Simkin et al., 1981) shows that $84 \%$ of subaerial,

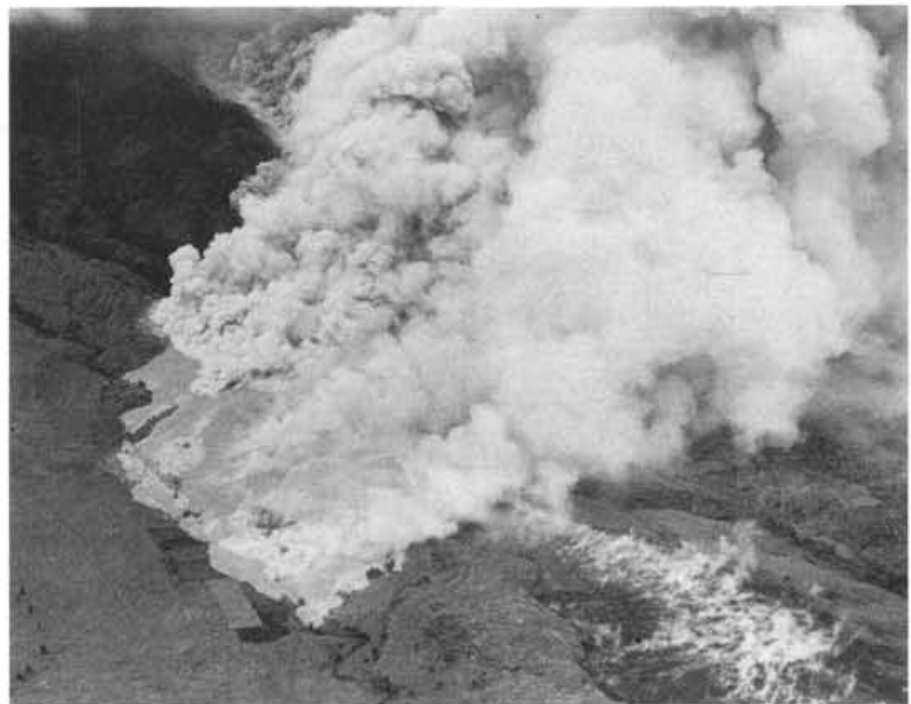

Figure 5: Nuées ardentes/pyroclastic flows near Bonga, Legazpi City, Philippines, September 23, 1984. Grazing land and several small vegetable plots have been overrun. On lower right is a pyroclastic flow from earlier in the same day, steaming because it had been rained upon.

historic eruptions are from subduction-zone voleanoes, such as those of the circum-Pacific. These tend to erupt explosively and are the most dangerous in terms of fatalities and widespread property damage. There seems to be a relationship between the length of preceding repose and the volume and violence of eruption; those that erupt less frequently may do so with the greatest violence. In other words, the volcanoes that are the most dangerous are the ones we know least about.

Arc voleanism is perhaps best understood in Japan, where eruptions are fairly frequent and where thirty volcanoes are presently monitored by university and governmental organizations. A few of them, such as Sakurajima and Asama, have been intensively studied (e.g., Aramaki et al., 1981). However, because the volcanoes of Japan range between basic and silicic strato-volcanoes and from giant calderas to small monogenetic cones, the behaviour of each must be studied individually, and few complete cycles of activity have been documented.

Predicting eruptions from seismic data has been reasonably successful in Japan, where there is commonly a period of seismic quiet immediately preceding an eruption. The Earthquake Research Institute of the University of Tokyo is working on means to improve the signal to noise ratio, with the objective of locating earthquake hypo-centers to within 100 metres. But such precision depends not only on good seismic data but also on a three-dimensional knowledge of the volcanic edifice and its surroundings.

Much less is known about voleanicity in the rest of the world's voleanic ares. In Indonesia, the Philippines and Papua New Guinea, existing observatories are fully extended just conducting routine monitoring and keeping track of numerous eruptions; leaving little time for basic research (Sudradjat and Tilling, 1984). In many South and Central American countries, volcanology has received little or no government support.

New Zealand and the conterminous United States have experienced relatively few historic eruptions and have only recently begun systematic studies directed toward eruption forecasting. Research at the University of Alaska in Fairbanks has contributed valuable information on the deep 
within the Platform and is represented by sand and clay deposits containing several ash tuff and tuffite members that allow correlation of the Redkino beds over large areas from the Dniester region of Podolia in the west to the Perm region over $2000 \mathrm{~km}$ to the east. These tuffs and tuffites are also distinct in the northern part of the Platform. In contrast to the Vilchan-Volhyn beds, the Redkino horizon and the Valday series as a whole extend beyond the limits of aulacogenes to fill syneclises, which outline the epicontinental basin.

The overlying Kotlin horizon has a similar distribution to rocks of the the Redkino level. Composed of argillites, siltstones, and a minor number of sandstones, the Kotlin horizon lies with an erosive base on the Redkino beds and sometimes rests on even older deposits.

The Vendian of the Russian Platform is terminated by terrigenous beds of the Rovno horizon, which are characterized by a specific assemblage of acritarchs, remains of numerous Sabelliditidae, rare Platysolenites, Aldanella and also by numerous trace fossils of Palaeozoic type (such as Phycodes, Treptichnus, and Gyrolithes) left by benthic invertebrates (Fedonkin et al., 1983). The stratigraphic position and paleontology of the Rovno horizon allow us to compare and correlate it with the Nemakit-Daldyn horizon of Siberia, which is also considered as terminating the Vendian.

It is clear now that the Vendian as a whole is a postaulacogene formation of the Russian Platform. Although the Vilchan-Volhyn deposits are confined to aulacogenes, the pretillite break seems abrupt eve:-where, whereas the preRedkino break is a transgressive disconformity.

\section{The Vendian on the Siberian Platform}

The stratigraphic equivalent of the Vendian in Siberia is the Yudomian, composed mainly of carbonates which unconformably overlap the underlying beds. Finds of soft-bodied Metazoa in the Upper Precambrian of Siberia show this to be a region where the Vendian system is widely distributed. The richest known locality for Vendian fauna was discovered in 1981 by us in the Khatyspyt Formation on the Olenek and Khorbusuonka rivers of northern Siberia. In the middle reaches of the Khorbusuonka River the Yudomian deposits can be divided into three formations (Fig. 2): the Maastakh (oldest), Khatyspyt, and Turkut (youngest), which succeed each other within the Khorbusuonka series (Komar, 1966; Shpunt et al., 1979).

The 52 m-thick Maastakh Formation lies with an erosive contact on Riphean dolomites and is composed of variegated volcanogenic rocks with laminae and cross-laminae, and containing beds of fine conglomerates. The upper $25 \mathrm{~m}$ is composed of yellow-grey thin-bedded dolomites.

The basal $12 \mathrm{~m}$ of the $120 \mathrm{~m}$-thick Khatyspyt Formation consists of sandstones and siltstones, but the major part of the unit is composed of limestones and light brown to black bituminous dolomites. Massive beds alternate with thin ones; these are sheared and contain many imprints of Metazoa. Trachybasalt tuff-breccias and tuffaceous siltstones occur in the upper part of the formation.

The Turkut Formation lies disconformably on bituminous carbonates and siltstones of the Khatyspyt Formation. It consists of alternating dolomite members, some containing stromatolites and lenses of microphytolites as well as layers of conglomerate, siltstone and tuff. The formation is $170-$ $230 \mathrm{~m}$ thick.

The Kessiusa Formation, which overlaps the Turkut dolomites, is composed mainly of clayey sandstones, siltstones with thin shales (in its lower part), and lenses of carbonates. Abundant and diverse trace fossils occur in this formation as do the oldest small shelly fossils (Missarzhevskiy, 1982).

Analogues of the Vendian are known practically on all continents, not only on platforms but also in geosynclinal regions. Everywhere they occupy the same stratigraphic posi- tion - higher than the tillites of the last Precambrian glaciation and lower than Cambrian deposits characterized by mass appearance of diverse skeletal fauna. Radioisotopic data show that the duration of the Vendian is similar to that of Phanerozoic periods and is not more than $100 \mathrm{Ma}$; the lower boundary has been dated at 650-680 Ma and the upper at 550-570 Ma (Keller and Krasnobayev, 1983). Although more work is needed, it is clear now that in the hierarchy of subdivisions of geological time the Vendian and the Cambrian have an equal status. This conclusion is based not only on historic and geological but also on palaeontological data.

\section{Palaeobiological Aspects}

Studies of the Vendian biota have opened a new and very important chapter in the palaeontological record, for these biota differ sharply from all later ones, in particular from those of the Cambrian. The latter are characterized by the abrupt appearance in the palaeontological record of various groups of Metazoa with a mineralized skeleton in the broad sense (for example, spicules, shells and tests) and, of course, the development of classical palaeontology was based mainly on studies of such skeletal remains.

The Vendian fauna as a whole are characterized by the diversity of taxa of high rank, though species diversity was low in the majority of groups. Reliable data on the divergence or origin of major groups are absent, and all phyla and classes of the Vendian fauna appeared abruptly.

At present the following groups of fossils have been established as occurring throughout the Vendian: procaryotes and life products of procaryotes such as stromatolites and microphytolites, acritarchs (microphytoplankton in the broad sense), unicellular and multicellular eucaryotes (fungi, multicellular vendotaenid algae with a non-mineralized thallus, calcareous algae in the uppermost Vendian, soft-bodied Metazoa, and groups of unclear systematic position), the oldest Metazoa with skeletons based on an organic matrix (Sabelliditida with a chitinous segmented tube), and trace fossils of benthic animals.

The first mineral skeletons, mainly tubular forms, appeared at the end of the Vendian. The biological uniqueness of the Vendian is emphasized by the occurrence of non-skeletal metazoans and macrophyte flora. Over the last ten years extensive localities containing the Vendian fauna have been discovered, in particular in the southeastern White Sea region, the Dniester region of the Ukraine and in Yakutia in the Olenek Uplift. The fossils collected in these regions now exceed in number and diversity all remains of Precambrian animals discovered outside the U.S.S.R, and a major collection is housed in the Palaeontological Institute of the Academy of Sciences in Moscow.

Vendian Metazoa (Fig. 3) are characterized by several peculiar features. Unlike all subsequent Phanerozoic fauna, those of the Vendian are represented by animals that do not have mineralized skeletons. The first small, simple forms with a tubular mineral skeleton appear only at the end of the Vendian. Abundant well-preserved imprints of soft-bodied animals indicate that during this period microphagous organisms were dominant among predators and necrophagues. There is every reason to suppose that relatively short food chains existed in the Vendian and, judging by trace fossils, the infauna did not constitute a large part of the benthic communities. Only in rare cases was the sediment subjected to biological processing. These peculiarities promoted the undisturbed preservation of soft-bodied Vendian organisms.

Gigantism is one of the typical features in several important Vendian faunal groups. This phenomenon is especially striking when non-skeletal Vendian animals are compared with small skeletal fossils of the Early Cambrian. Medusoid forms with a diameter of more than half a meter were not rare in the Vendian, and some feather-shaped colonial polyps reached one meter or more in length. It is possible that gigantism of 
maintained and hope, for the sake of the 70,000 people living in and near Rabaul caldera (Fig. 6), that shortterm precursors can be detected, characterized, and interpreted in time. Even in a country such as Canada, where the frequency of eruptions is in the order of 200 to 300 years, eruption forecasting has become a factor in deciding whether or not hydroelectric dams should be built on rivers that may be affected by future eruptions.

Finally there is the problem of false alarms. How of ten can we "cry wolf" and still expect a response from the public and from government authorities? In 1976, the small phreatic eruption of La Soufrière on Guadeloupe, West Indies, was thought to be the precursor of an impending larger, magmatic eruption. Consequently 74,000 residents were ordered to evacuate to avoid an eruption that never materialized, and voleanologists were subsequently blamed for the months of unnecessary personal and economic hardship and loss of tourism revenue (Fiske, in Bovd, 1984).

A major factor contributing to the crisis here was the lack of critical pre-eruption baseline data that could be compared with results of monitoring studies obtained after the eruption began. This problem was compounded by the fact that two scientific teams involved in the studies disagreed strongly on the interpretation of monitoring data. This disagreement fully and sensationally exploited by the media that had unlimited access to the working scientists - understandably added to the confusion among the government officials and the public.

In contrast, when Soufrière Volcano on the nearby Caribbean Island of St. Vincent began to erupt explosively on April 12, 1979 , there was no doubt whatsoever that the eruptions posed a hazard to the people living on the volcano's slopes, because adequate baseline monitoring studies had been initiated several years before the eruption. More than 20,000 people spontaneouslv left the danger areas, and the St. Vincent government enforced the evacuation until the explosive phase of the eruption ended. Because of the existing pre-eruption data, good communication between working scientists, a single rather than multiple interpretation of monitoring data, and no media access to the working scientists, the socio-economic impact of 1979 voleanic erisis at St. Vincent was minimized (F iske, ibid.).

By its very nature, eruption forecasting entails a social responsibility far greater than that borne by most of the earth sciences. Providing the best possible predictions often requires working close to the source of danger - a risk that most voleanologists are prepared to accept - but
Figure 8: El Chichon after the catastrophic MarchApril 1982 eruption, which destroyed the central dome, forming in its place a new crater about $1 \mathrm{~km}$ wide and $300 \mathrm{~m}$ deep.

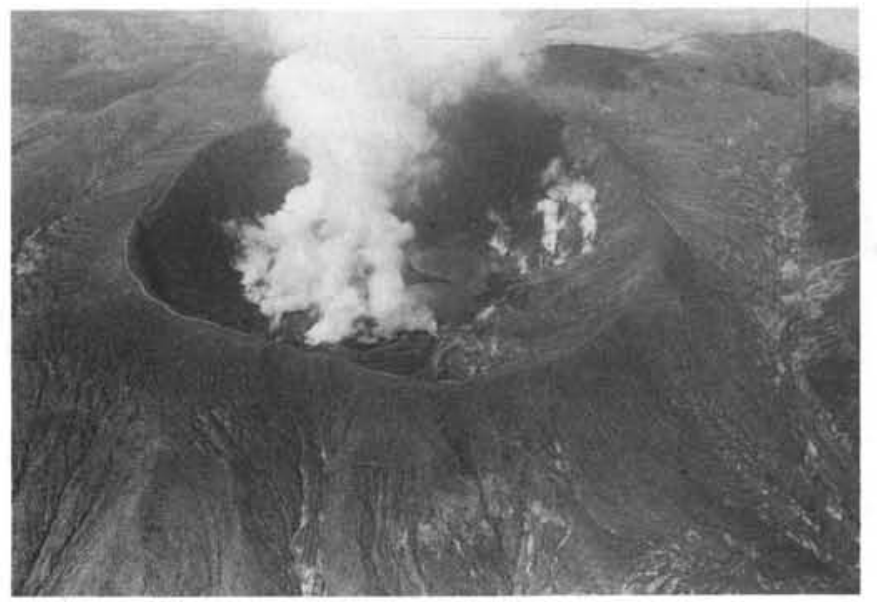

no amount of dedication and care can completely eliminate false alarms or misinterpretation of available scientific data.

\section{Preparing for a Crisis}

The issuing of an eruption alert mav be the end result of vears of geological study and monitoring bv scientists, but it mav also be the beginning of public confusion or chaos if no contingency plan has been prepared. If the eruption alert is to serve its intended purpose, the scientists and the public safety groups must be in communication both before and during an eruption crisis, and each must be aware of the responsibilities and limitations of the other. At Mount St. Helens in 1980 a central task force delegated specific areas of responsibility to each of the Federal, State, and local agencies concerned with monitoring or public safety. Scientists provided important volcanic-hazards information in the preparation of a contingency plan, which was issued on April 9, more than a month before the catastrophic eruption on May 18 (Tilling, 1981). The result was a fairly orderly closure and evacuation of threatened areas and regular release of emergency information bulletins.

Such is not always the case. Despite the presence of 14 active volcanoes within its borders, Mexico has never had a national program of volcano monitoring or volcanic-hazard assessment. The March-April 1982 eruption of El Chichon in southeastern Mexico (Figs, 7 and 8) came as a complete surprise; there was no contingency plan and no interface between scientists and civil defense authorities. Ash-clogged roads and lack of coordination delayed both evacuation of residents and access of scientists and monitoring equipment to the volcano (Fig. 9). In the turmoil and confusion of the El Chichon eruption, an estimated 2,000 people perished - the worst voleanic disaster in Mexico's recorded history (Alcayde, 1983; Duffield, Tilling and Canul, 1984).

Because response to a volcanic crisis may require a multinational effort, it is essential that international lines of communication be established and regulatory procedures thoroughly understood by officials in both the host and assisting nations before a crisis develops. It is of prime importance that there be contact between scientists in the host and assisting countries before a crisis develops, and a clear understanding that voleanological teams should receive a formal invitation from, and be under the supervision of, the host country.

In 1982, offers of aid by the USGS during the El Chichon crisis were at first declined by the Mexican Government, and collaborative work resulted only after an appeal to their authorities from Mexican scientists seeking help. Bureaucratic delays also 

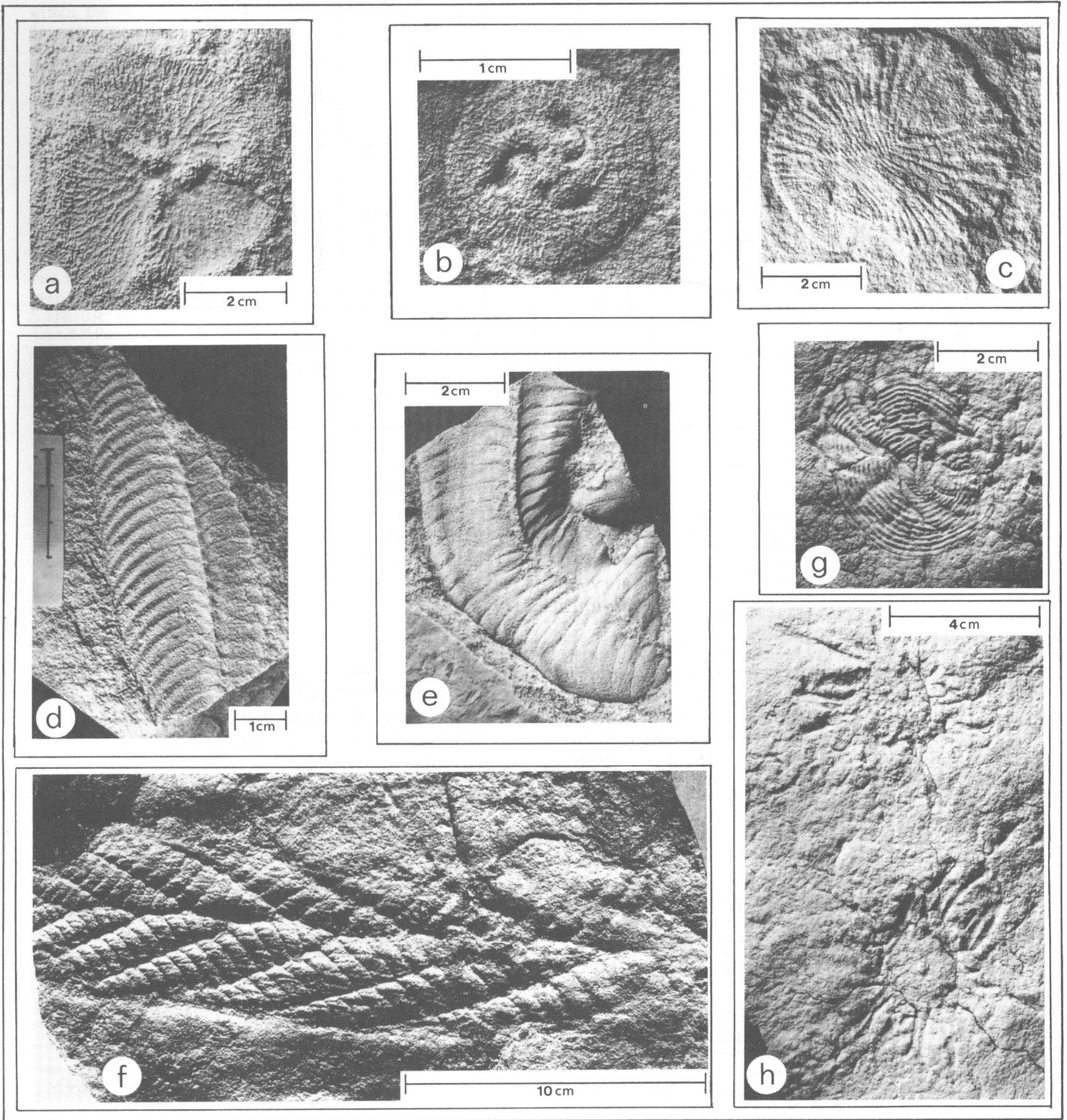

Figure 3: Some typical representatives of the Vendian soft-bodied metazoans from the Ust-Pinega Formation (Redkino horizon, Valdai series), White Sea region: a) Albumares brunsae Fedonkin, b) Tribrachidium heraldicum Glaessner, c) Dickinsonia costata Sprigg, d) Pteridinium nenoxa Keller, e) Inkrylovia lata Fedonkin, f) Charnia masoni Ford, $g)$ Ovatoscutum concentricum Glaessner et Wade, $h$ Hiemalora stellaris Fedonkin. 
Australia and now also the recipient of seientific assistance from Japan and New Zealand. Similarly, in recent years volcanologists from France, Iceland, Italy, Japan, the United States, and other developed countries have responded, both informally and through bilateral agreements, to requests for technical assistance from countries such as Chile, Costa Rica, Ecuador, Indonesia, (Sudradjat and Tilling, 1984), Mexico, and in late 1984, the Philippines.

Such rapid-response units maintained in a state of readiness by established observatories may provide back-up for an early-warning system in developing countries, or even in developed countries, such as Canada, where the frequency of eruptions is too low to justify maintaining fully equipped volcano observatories. But as in the case of remote stations, the benefits offered by mobile, rapid-response units must be balanced against their possible negative impact.

Relying too heavily on such units could foster a sense of false security that could detract from the development of local response capability. Also, some volcanologists feel that expensive equipment should not be kept "on hold," waiting to monitor an eruption that has already started. By the time most mobile units have responded to a request and have their instruments in place, the early precursor events - most valuable for future forecasting - may have already gone undetected.

An international mobile early-warning system for volcanic eruptions that seems to overcome some of these concerns has been proposed by the Division of Earth Sciences of Unesco, following the recommendations of three regional workshops of volcanologists held in 1983 in Jakarta, San Jose (Costa Rica), and Rome. The Unesco equipment might be used during non-crisis times for training purposes and for helping national institutions acquire base-line data.

\section{The Need for Training}

Only about one percent of active and potentially active volcanoes in the world are now being monitored, and few of the residents living near them have any concept of the process or consequence of an eruption. At El Chichon, for example, the devastating 1982 eruption was preceded by weeks of precursory seismic activity that was noticed and even recorded by local people, but never interpreted. Local technicians, unaware that the mountain posed any danger, continued to routinely change, file and send the seismic records to Mexico City without the careful examination that the situation demanded. The need in such situations is clearly not just for more instruments, but also for more training. In countries such as Indonesia, with 130 active volcanoes, even the training and support of sufficient technicians and volcano watchers are formidable tasks (Sudradjat and Tilling, 1984). Ongoing international support for training is long overdue.

A proposal has been recently submitted to Unesco, to provide in the SW Pacific training at three levels: professional voleanologist, technician, and volcano watcher. As part of this program New Zealand has proposed to offer a one-year training period for voleanologists and a shorter course for technicians and volcano watchers.

\section{The Need for International Support}

Like any other civil-defense program, volcano monitoring and eruption-warning systems require stable, long-term funding in order to be effective. For many developing nations, where the monitoring of dangerous volcanoes is of vital concern, the main source of such support is through multilateral or bilateral international aid programs. Most nations which have an established volcanological capability, like the U.S.A., Japan, Australia, New Zealand, and Italy, provide some bilateral assistance to less developed nations of the $\mathrm{SW}$ Pacific and Latin America, and the UN also contributes.

There is, however, some doubt within the volcanological community as to whether the present mix of bilateral and multilateral aid can provide the stable financial base that is required to ensure ongoing programs. There is general agreement that better coordination of existing resources is needed. Organizations like the Circum-Pacific Council for Energy and Mineral Resources (CPCEMR) could assist, for example, in supporting exchanges of scientific data and personnel between developing and more advanced countries, helping to extend the PEACESAT communication satellite system for exchanging volcano monitoring information, and in organizing technical sessions and workshops on volcanology. And of course there is a need to promote a consistent and stable, long-term source of funds for international voleanology programs.

In order to advance eruption forecasting, it is be essential for some organization within the field of volcanology and with international contacts to coordinate rapid-response efforts and training programs and to act as a clearing house - in effect, to serve as the operational arm of international funding agencies. A possible organization to fill this role might be the World Organization of Volcano Observatories (WOVO), which was inaugurated in 1981 to create or improve ties between volcanological observatories and institutions, to facilitate exchanges of views and experience, to maintain an inventory of instrumentation and manpower, and to promote funding from international organizations (Sigvaldason, 1981).

WnVn's clearly focussed objectives and a membership that includes representatives of virtually every country engaged in monitoring active volcanoes would seem to make this organization a good point of contact for the international volcanological community. However, apart from some informal activities, wOVo has been unable to mount any major program because of lack of adequate funding.

Volcano monitoring is a multidisciplinary science of truly global scope. Providing effective eruption forecasts requires a constant state of readiness and the coordinated effort of scores of earth, atmospheric, oceanographic, and space scientists, government and international agencies. Among such a diverse group communication is probably the single most important key to success. In the two years before the next scheduled workshop on volcano forecasting takes place at the CPCFMR meeting in Singapore, it is safe to forecast that many volcanic eruptions will occur in the Pacific Region alone and it will again be time to review our ability to predict them.

\section{Acknowledgments}

This article summarizes the background, results and recommendations of a workshop on "Pacific Volcanology; Forecasting Eruptions" held in Hilo, Hawaii in June 1984. This was the largest gathering to date of specialists directly involved with eruption forecasting. The meeting was sponsored by CPCEMR, IAVCEI, WOVO, IUGS, ILP, Unesco, USGS and the Office of Foreign Disaster Assistance of the U.S. Agency for International Development. The participants were R.W. Johnson (Australia), J.G. Souther and W.W. Hutchison, (Canada), O. Gonzalez-Ferran, (Chile), C. Ropain U. (Colombia), E. Malavassi (Costa Rica), Minard Hall (Ecuador), A. Santano de Zamora (El Salvador), I. Everingham and P. Rodda (Fiji), M. Arnould and J-L Cheminee (France), E.R. Quebec (Guatemala), G.E. Sigvaldason (Iceland), Adjat Sudradjat (Indonesia), F. Barberi, R. Scarpa, and L. Villari (Italy), S. Aramaki, K. Ono and D. Shimozuru (Japan), S. de la Cruz-Reyna and G. Salas (Mexico), J.W. Cole, J.H. Latter and I. Nairn (New Zealand), Ben Talai (Papua New Guinea), A. Parodi I. (Peru), R.S. Punongbayan (Philippines), M. Hashizume and John P. Herakovich (UN), J.D. Christensen, R.W. Decker, J.J. Dvorak, D.B. Jackson, L. McClelland, C.G. Newhall, A. Okamura, D.W. Peterson, J.A. Reinemund, M. Sato, D.A. Swanson, R.I. Tilling, T.L. Wright and M.T. Halbouty (U.S.A.). 


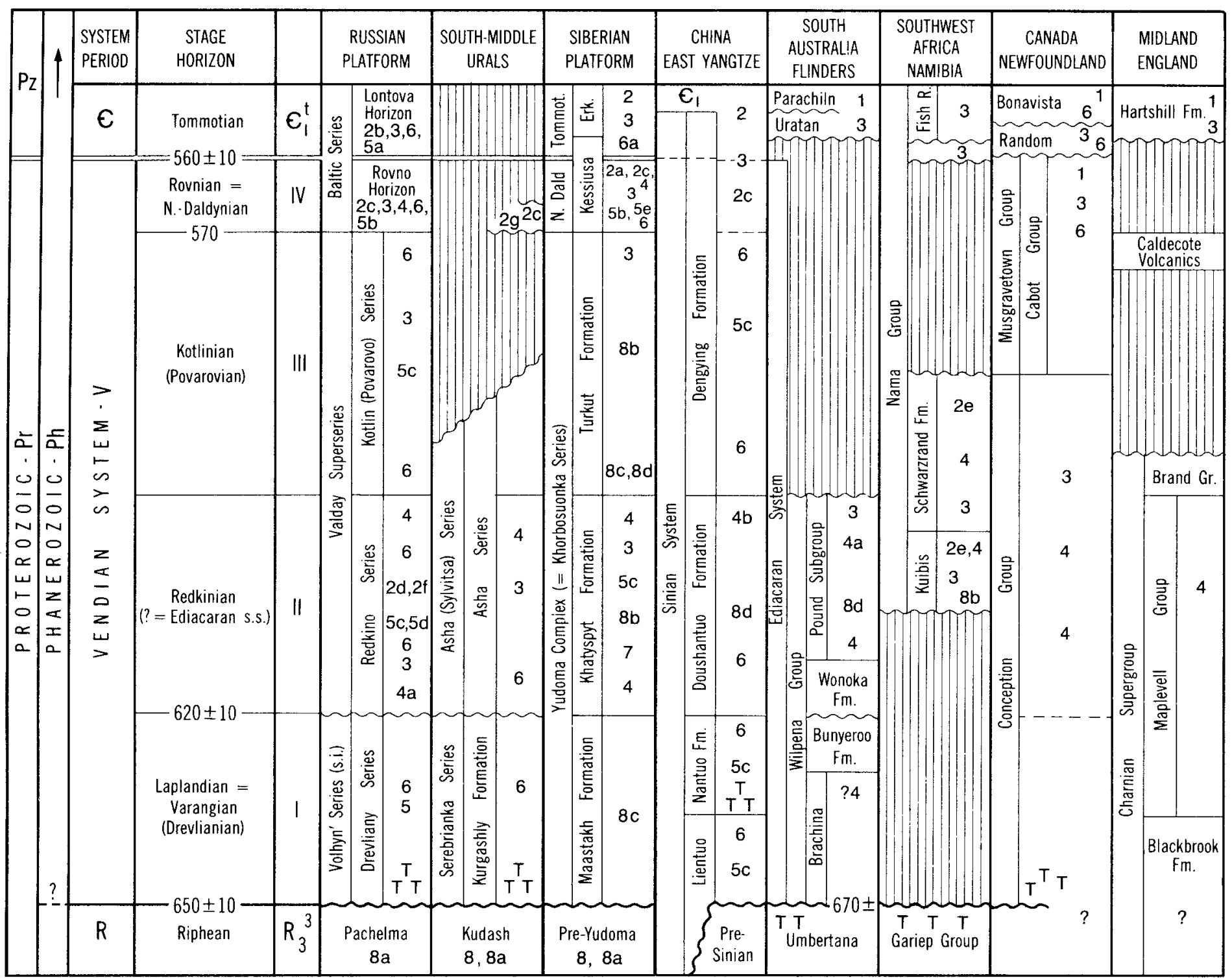

Figure 4: Correlation of the Soviet Vendian with the most important Upper Proterozoic sequences elsewhere. Key to fossils: 1 -skeletal Metazoa, 2 - Tommotian assemblages (2a-Anabarites tris., $2 b$ - Platysolenites, $2 c$ - Sabelliditida, 2d - Calyptrina, 2e - Cloudina, $2 f$ - Redkinia, $2 g$ - Sabellitidita beds of East Urals slope); 3 trace fossils; 4 -Vendian soft-bodied fossils (4a - Type assemblage: Cyclozoa, Dickinsoniidae, Vendomiidae, Charniidae, Pteridiniidae, Tribrachidium; $4 b$ - Liaoning assemblage); 5 -algae, Vendotaenides (5a - Dvinia, $5 b$ - Tyrasotaenia, 5c - Vendotaenia, 5d - Eoholynia, 5e - Korilophyton); 6 - acritarchs (6a - Lontova assemblage); 7 - Chuariamorphida; 8 - stromatolites (8a - microphytoliths, $8 b$ - Yudomian assemblage with (8c) stromatolites and (8d) microphytoliths); $T$ - tillites. 